\title{
1,n-Alkanedithiol (n = 2, 4, 6, 8, 10) Self-Assembled Monolayers on Au(111): Electrochemical and Theoretical Approach
}

\author{
Deyu Qu, Byung-Cheol Kim, Chi-Woo J. Lee, and Kohei Uosaki ${ }^{\dagger}$
}

\author{
Department of Advanced Materials Chemistry, Korea Universitv, Jochiwon, Chmonam 339-700. Korea \\ "E-mail: culee akorea.ac.kr \\ Phrisical Chemistry Laboratory, Division of Chemistry. Graduate School of Science, Hokkaido Cmiversity, \\ Sapporo 060-0810, Japan \\ Received June 20. 2009. Accepted September +. 2009
}

\begin{abstract}
The structures of $1, n$-alkanedithiol $(n=2,4,6,8,10)$ self-assembled monolayers (SAMs) on a Au( 111 ) substrate were investigated by electrochemical measurements and theoretical calculations. The results of the experimental techniques indicated that the dithiols, except $n=2$, showed an upright molecular structure in the SAMs, in which alkanedithiols were bound to the Au surface via only one thiol functionality and the other one faced up to the air. The results also suggested that the formed dithiol SAMs were densely packed and highly oriented. Except ethanedithiol, which was thought to fom a bilayer, the reductive desorption peak potentials of $l$, $n$-alkanedithiol $(n=4,6,8,10)$ SAMs were more negative than those of the corresponding monothiol ones in $0.1 \mathrm{M} \mathrm{KOH}$ solutions. This illustrates that the dithiol SAMs had higher stability than the corresponding monothiol ones. The major part of the high stability may be attributed to the van der Waals interaction among the sulfur atoms on top of the dithiol SAMs. The molecular modeling calculation showed that the structures of dithiol SAMs were similar to those of the corresponding monothiol SAMs and that all the dithiol SAMs, except ethanedithiol, were more stable than the corresponding monothiol SAMs. The calculated energy differences between dithiol and monothiol SAMs decreased with the increment of alkyi-chain length.
\end{abstract}

Key Words: Alkanedithiol. Alkanethiol, Self-assembled monolayer, Au(111), Electrochemistry

\section{Introduction}

Self-assembled monolayers (SAMs) of organic thiols on gold have been extensively studied in past decades. ${ }^{1,2}$ They provide a good molecular candidate to be used in many application areas as well as a highly reproducible model sy stem for understanding organic interface. The SAMs with $\omega$-functional groups have been of particular interest. ${ }^{1-\hat{*}}$ Those functionalities on top of SAMs mainly control the surface properties of the organic film and provide the possibility to connect with other functional units. Among them, thiol-terminated surface, with their high affinity to metals. can serve as templates for the formation of metal film or metal wires at SAM-ambient interface by preventing the diffusion of metal into SAMs and formation of a short circuit. ${ }^{3-7,1+1 ;: 2--35}$ It can also be used as building blocks for constructing multilayers. ${ }^{7 ? .35}$ The most suitable constituent for the formation of thiol terminated SAMs is dithiol. Dithiol SAMs have been utilized to make nanodevices. measurements of electricity transport and multilayer formation ${ }^{3-7.1+1}{ }^{1}: 2-38$ But most of those studies only focus on the electronic properties of dithiol SAMs. Compared to the well studied monothiolate SAMs. there are relatively less reports focused on the structure and growth of dithiol SAMs.

Due to the two thiol groups existing in the dithiol molecule. the possibility to form a bridge or loop-like structure, in which a dithiol molecule adsorbed flat on a Au substrate via two sulfur atoms. can not be nuled out in the formation of dithiol SAMs. For example, 1,6-hexanedithiol was found to be adsorbed flat on Au revealing a parallel molecular orientation from the gas phase. ${ }^{39}$ SAMs of 2-monoalkylpropane-1,3-dithiol derivatives. $\mathrm{CH}_{3}\left(\mathrm{CH}_{2}\right) n \mathrm{CH}\left[\mathrm{CH}_{2} \mathrm{SH}\right]_{2}$. were also reported to bond $\mathrm{Au}$ with the two thiol groups from a solution. ${ }^{401}$ On silver. dithiol molecules are usually adsorbed as dithiolates by forming two Ag-S bonds. ${ }^{41-44}$ This looping construction will impede the formation of thiol-terminated SAMs and. further more, inhibit its application in molecular electronics.

On the other hand. other studies showed that alkanedithiol. as well as aromatic dithiol. adsorbed on gold surface from solution as monothiolate $v i a$ only one thiol functionality. ${ }^{22-38.41,45.55}$ In this upright molecular stnucture. the unbound thiol group is pendent with respect to the Au substrate and serves as the platform for the applications. such as the preparation of copper (I)-dithiol or CdS nanoparticle-dithiol multilayer thin filmss, the formation of nultilayer through disulfide linkage spontaneously or electrochemically, the measurement of electron transfer through single molecule or the construction of metalmolecule-metal sandwich structure ${ }^{3.2-03 i-38}$ However. the quality of those thiol terminated surface has been debated. Loose pack. ill-defined dithiol adlayers. which were prepared by simple immersion of gold substrate into a solution of dithiol. were reported ${ }^{52,52}$ In order to obtain compact thiol-terninated dithiol SAMs. different formation methods were proposed including protection of one thiol-group as thiolacetate and the following regeneration of $\mathrm{SH}$ on top of the formed dithiol SAMs and using organodithiols with more rigid backbonds. The control of formation condition such as using different solvent. removal of oxygen from SAMs formation solution were also suggested. ${ }^{2 .-25,31.31,41.45-51.54-57}$ Formation of disulfide bond through the terminated free thiols on top of dithiol SAMs were reported as well. ${ }^{32-25,48.49}$ Those interlayer and intralayer 
disulfide linkage will result in the formation of multilayer and rearrangement of molecular configuration of dithiol molecules in the SAM. respectively:

In this study, a series of densely packed. looping structure free. thiol-terninated alkanedithiol SAMs with higher stability' than those of monothiolate SAMs were prepared. Those thiolterminated dithiol SAMs were examined by electrochemical measurements. As a comparison. the corresponding monothiolate SAMs were also investigated. With the aid of theoretical calculation. the structure of thiol-terminated alkanedithiol SAMs was determined. Our goal was to clarify some previous contradiction and to provide information of the stnicture. quality and stability of alkanedithiol SAMs on Au(111) substrate. The possibility of the fornation of disulfide was also discussed.

\section{Experimental Section}

Materials. All chemicals were of the best quality available commercially and used as received. Water was purified using a Milli-Q purification system (Millipore). Ultrapure Ar gas $(99.9995 \%)$ was purchased from Air Water.

$\mathrm{A} \mathrm{Au}(111)$ single crystal, which was used in electrochemical measurements. was prepared from a gold wire $(99.999 \%$ pure. Tanaka Precious Metal) by the Clavilier method and was then cut and mechanically polished ${ }^{58}$ The real surface area of the $\mathrm{Au}(111)$ single crystal electrode was estimated from the cathodic current corresponding to the reduction of $\mathrm{Au}$ oxide to be $0.078 \mathrm{~cm}^{-}$

Electrochemical Measurements. Electrochemical measurements were performed in a three-compartment electrochemical cell using an EG\&G 283A potentiostat. The electrode potential was referred to a $\mathrm{Ag} / \mathrm{AgCl}$ (saturated $\mathrm{NaCl}$ ) electrode and a Pt wire was used as a counter electrode. The electrolyte solution was deaerated by bubbling Ar gas for at least $30 \mathrm{~min}$ before each experiment

Ellipsometry. Ellipsometry measurements were performed using a SOPRA. GESP-5 ellipsometer in a wavelength region of $300-800 \mathrm{~nm}$ with an incident angle upon the sample of $75^{\circ}$ at Hokkaido University. A software program (WINELLI) was employed to determine the monolayer thickness. The refractive index of the SAMs was assumed to be $1.45^{3}$

SAMs Preparation. The monothiols ( $\mathrm{C} 2 \mathrm{SH} . \mathrm{C} 4 \mathrm{SH} . \mathrm{C} 6 \mathrm{SH}$. $\mathrm{C} 8 \mathrm{SH}$ and $\mathrm{Cl} 10 \mathrm{SH}$ ) were self-assembled on $\mathrm{Au}(111)$ surface by simple immersion of $\mathrm{Au}(111)$ substrate into an ethanolic solution containing $1 \mathrm{mM}$ of respective alkanethiol for 12 hours. The dithiol (C2S2, C4S2. C6S2, C8S2 and C10S2) SAMs were prepared by immersing the Au substrate in an ethanol solution of $1, n$-alkanedithiol $(n=2.4 .6 .8 .10)$ with a concentration of $1 \mathrm{mM}$ for 2 or 3 hours. The dithiol solutions were saturated with Ar before the incubation and were kept under Ar atmosphere and in the dark during the formation of dithiol SAMs.

Theoretical Method and Molecular Modeling. Molecular modeling calculations for SAMs and single thiol molecule bound to gold surface were performed with a HyperChem (Hypercube. Inc) software program on a PC with an Intel Pentium D 2.66 GHz microprocessor. ${ }^{5 y^{\prime}}$
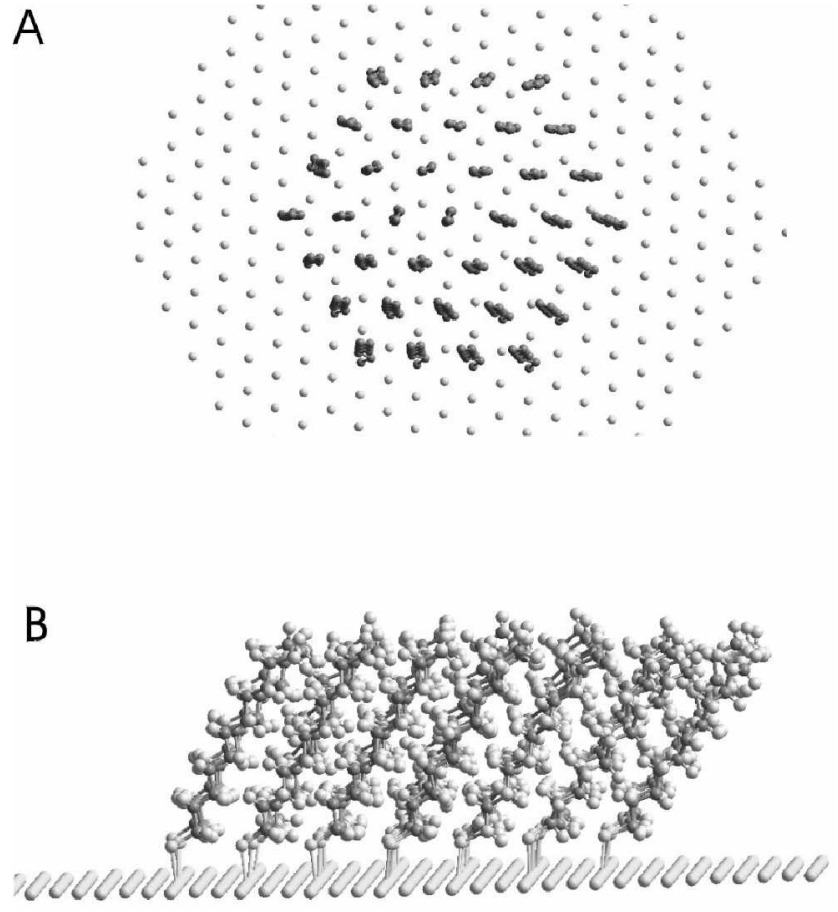

Figure 1. Simulated structure of mono/dithiol SAMs on a Au( 111 ) substrate surface with a fixed distance between two molecules of $5 \AA$ (A: top view, B: side view).

The initial structure of each monothiol (C2SH. C4SH, $\mathrm{C} 6 \mathrm{SH} . \mathrm{C} 8 \mathrm{SH}$ and $\mathrm{Cl} 10 \mathrm{SH})$ and dithiol $(\mathrm{C} 2 \mathrm{~S} 2 . \mathrm{C} 4 \mathrm{~S} 2 . \mathrm{C} 6 \mathrm{~S} 2$. C8S2 and C10S2) molecules were obtained by a model builder. The stable structure was obtained through 'geometry optimization' using ab initio quantum mechanical calculation with a ' $6-31 \mathrm{G}^{*}$ ' basis set. The atomic charges for each atom in the molecule were obtained and used to calculate the electrostatic term of potential energy in molecular mechanics.

The Au(111) surface coordinates were obtained from "crystal builder ${ }^{.61}$ and achieved manually by rotating coordinates of the crystal to find the cross section of Au(111). The monothiol and dithiol molecules were then deposited on $\mathrm{Au}(\mathrm{Il} 1 \mathrm{l})$ surface with a distance of $5 \mathrm{~A}$ as shown in Figure 1. The SAMs structure contained 37 thiol or dithiol molecules. As shown in Fig. la, the center molecule was encircled by 6,12 and 18 molecules as $\mathrm{I}^{\text {st }}, 2^{\text {thil }}$ and $3^{\text {thi }}$ layer of surrounding molecules. respectively. In this configuration, the center molecule was used as a representative of molecules in SAMs.

$\mathrm{MM}+$ force field, which is an extension of MM2, developed by Allinger and co-workers to represent the potential energy was used in this study. ${ }^{61}$

The structures obtained through 'geometry optinization' are not optimum geometry, because the potential energy surfaces are too complex for simple geometry optimization to find the real optinum structure. A molecular dynamics simulation for more than $100 \mathrm{ps}$ depending on the size of molecule with keeping the coordinates of all $\mathrm{Au}$ atoms was performed. Then a $2^{\text {tikl }}$ molecular dynamics simulation for 1 ns was performed from the starting point with the final structure of the previous simulation. The constant tenperature of $300 \mathrm{~K}$ was used in the simulation 
The calculated angles of the monothiol and dithiol molecules in the SAM with respect to the surface normal of All (I11) substrate were compared with the experimental ones and the validity of present calculation was justified.

One of the purposes of this calculation was to determine the stabilization energy of thiol molecules in SAMs due to their intermolecular interactions. To achieve this. the energy of center molecule in each SAM was used. 100 snapshots with the same intervals from the result of lns molecular dy namics for every SAM on Au(111) were collected. The energy of each snapshot was calculated by performing 'single point' calculation.

\section{Results and Discussion}

Linear Sweep Voltammogram. The linear sweep yoltammograms (LSV) of $1, n$-alkanedithiol $(n=2,4,6,8.10)$ SAM on a $\mathrm{Au}(111)$ substrate were recorded in a $0.1 \mathrm{M} \mathrm{KOH}$ solution with a potential scan rate of $20 \mathrm{mV} \mathrm{s}^{-1}$ as are shown in Figure 2a. As a comparison, the LSV of alkanethiol ( $\mathrm{C} 2 \mathrm{SH}$ to $\mathrm{ClOSH})$ were also recorded and are shown in Figure 2b. In Figure $2 \mathrm{a}$. a series of sharp cathodic peaks corresponding to the reductive desorption of the C2S2. C4S2, C6S2, C8S2 and C10S2 SAM were observed at $-0.885,-0.908,-0.970,-1.035,-1.105 \mathrm{~V}$. The reductive peak potentials of dithiol SAMs were negatively shifted as alkyl chain length was increased from two to ten. This chain length dependent phenomenon was also found in the reductive desorption of alkanethiols in previous studies and was reproduced to be shown for comparison in Figure

(a)

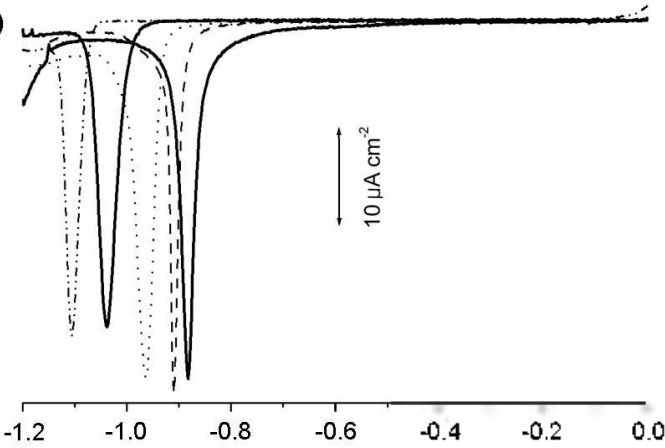

(b)

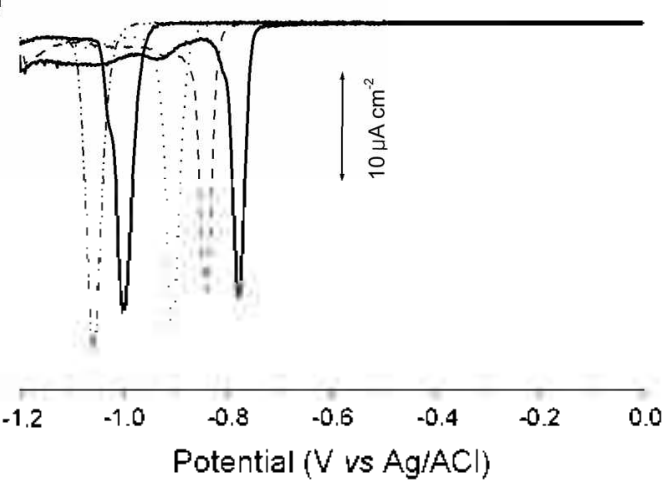

Figure 2. Linear sweep voltanmograms of (a) $1, n$-alkanedithiol $(n=$ $2,4,6,8.10)$ and (b) alkanethiol $(n=2,4,6,8,10)$ SAM on a $\mathrm{Au}(111)$ electrode in $0.1 \mathrm{M} \mathrm{KOH}$ solution with potential scan rate of $20 \mathrm{mV} \mathrm{s}^{-1}$.
$2 b$. ${ }^{6,03}$ As demonstrated in prior work, there are several interactions involved in the organothiol SAMs on Au substrate. including S-Au interaction, chain-chain interaction, headgroupheadgroup and headgroup-environment interaction. The overall balance of those interactions governed the structure and stability of the SAMs. Increase of the chain length will increase the stability of the SAMs and. therefore. result in negatively shifting the peak potentials of the desorptive reduction. Notice that the reductive desorption peak potential of $\mathrm{C} 2 \mathrm{~S} 2$ was rather similar to that of the $\mathrm{C}+\mathrm{S} 2$. implying some deviation from simple dithiol SAM formation such as a bilayer formation of C2S2. The fommation of C2S2 bilayer was checked by the ellipsometry measurement. The measured ellipsometric thicknesses of $\mathrm{C} 2 \mathrm{~S} 2$ and $\mathrm{C} 4 \mathrm{~S} 2$ layers on a vacum-evaporated $\mathrm{Au}$ substrate surface were found to be $0.65 \pm 0.04 \mathrm{~mm}$ and $0.67 \pm$ $0.03 \mathrm{~lm}$. respectively. This suggests that a C2S2 bilayer was formed and the thickness of this bilayer was similar to that of $\mathrm{C}+\mathrm{S} 2$ monolayer. which resulted in the sinular reductive peak potential in the two samples. This observation is in agreement with the previous report. in which a bilayer will be formed on Au by C2S2 in an ethanolic solution even in its sub-nonolayer coverage. 46 Other multilayers were not noticed with the experimental conditions of the dithiols investigated in this study, reflecting that formation of SAMs and multilayers is the sensitive function of the experimental variables of medium. concentration impurities and immersion time among others.

To clearly see the relationship between the reductive desorption peak potentials in different alkyl chain-length thiol and dithiol. the reductive peak potential and the peak potential difference between thiol and dithiol were plotted as a function of the number of carbons in those molecules and are shown in Figure 3 and 4 . respectively. Figure 3 shows that the reductive peak potentials of dithiol SAMs were always more negative than those of the corresponding thiol SAMs. which indicates that the dithiol SAMs are more stable than the corresponding monothiol SAMs. As shown in Figure t. the peak potential differences between the thiol and dithiol with the same chain length were greater than $50 \mathrm{mV}$. and had a trend of decrement with chain length increased. This negative shift in reduction

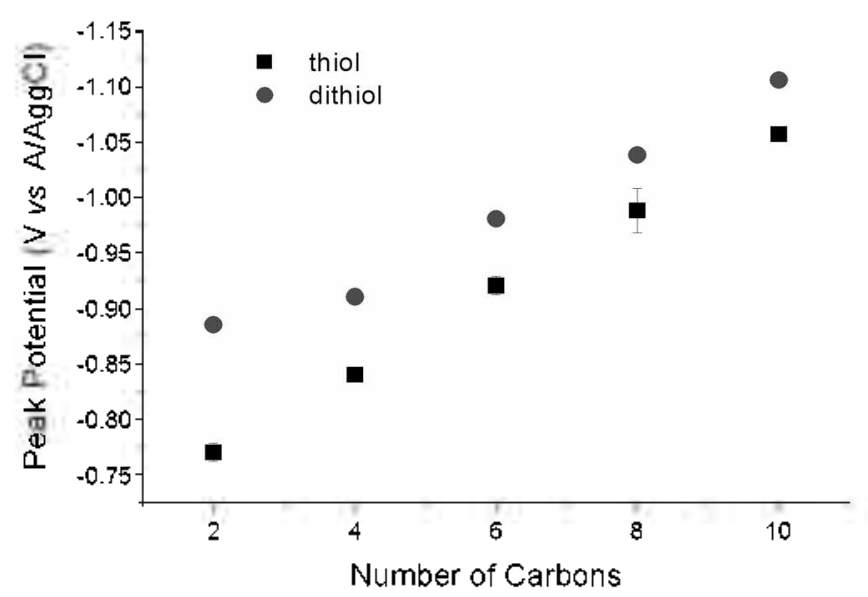

Figure 3. Dependence of reductive desorption peak potential of dithiol SAMs (circle) and monothiol SAMs (rectangle) on the number of carbon atoms in the molecules. 
potential from alkanethiol to alkanedithiol SAMs can be attributed to the different headgroup-headgroup interaction in the two types of SAMs. The S-S interactions on dithiol SAMs are higher than that of $\mathrm{CH}_{3}-\mathrm{CH}_{3}$ on thiol SAMs and therefore, make the dithiol SAMs reductive peak position negatively shifted. It was surprising at first to obsere the chain length dependence of the reductive potential shift between alkanethiol and alkanedithiol SAMs, since. for different chain length, the headgroupheadgroup interaction difference $\left(\mathrm{E}_{\mathrm{S}-\mathrm{s}}-\mathrm{E}_{\mathrm{CH} 3-\mathrm{CH} 3}\right.$ ) would be the same and the chain length independence would be expected. The observed chain length dependent phenomenon can be explained by the change in the SAMs stnicture. the contribution of S-S interaction to the total energy of SAMs and the energy of S-S interaction itself followed with the change of alkyl chain length. It has been confirmed that the structure of alkanethiol SAMs, eg. tilt angle and tilt direction, will change with alkyl chain length. The similar observations were found in the dithiol SAMs investigated in the theoretical study (vide infra). The structure of dithiol SAMs will affect the S-S interaction energy. The increase in chain length will increase the energy of chain-chain interaction and. therefore. the relative contribution of S-S interaction to the total energy of dithiol SAMs will decrease upon increasing the alkyl chain length. Since the structure of SAMs were determined by the overall balance of the different energies contributing to the formation of the SAMs. the decrease of S-S interaction energy contribution will cause the SAMs structure change unfavored for the S-S interaction. This may result in the decrease of the contribution of the $\mathrm{S}-\mathrm{S}$ interaction energy with chain length increased.

The charges associated with the reductive desorption of those dithiol SAMs were found in the range of $100( \pm 5 \%) \mu \mathrm{C}$ $\mathrm{cm}^{-\hat{*}}$ without double-layer charge correction, which is in good agreement with the value for the reductive desorption of alkanethiolate SAMs with saturated coverage of a $(\sqrt{3} \times \sqrt{3}) R$ $30^{\circ}$ structure formed on a $\mathrm{Au}(111)$ surface. ${ }^{62.63 .66-68}$ It should be mentioned that this value consists of $70 \%$ of Faradaic charge for one-electron reduction of SAMs with saturated coverage of a $(\sqrt{3} \times \sqrt{3}) R 30^{\circ}$ structure and $30 \%$ of capacitive (non-Faradaic) charge. $62 \% 6 \%$ - 58 fact that the constant charge corresponding to the full monolayer coverage of dithol

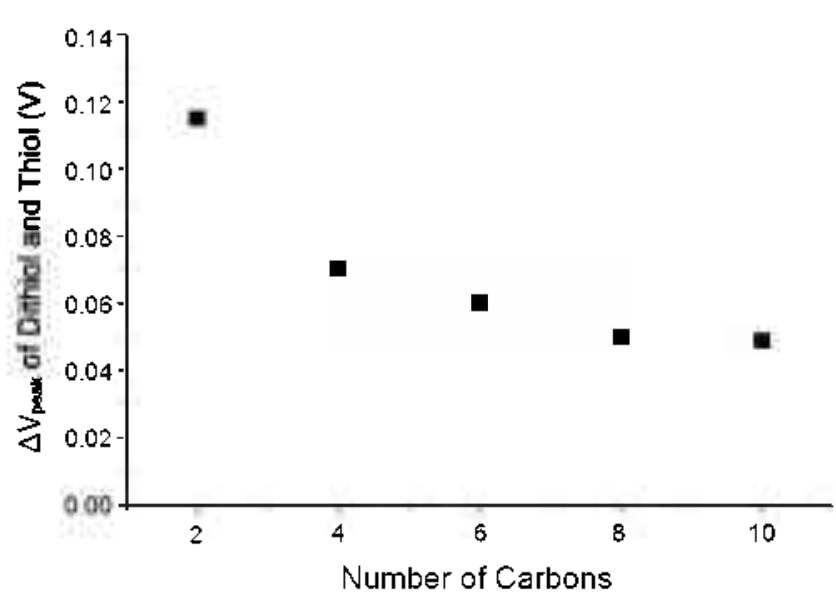

Figure 4. Plot of reductive desorption peak potential shift as a function of chain length.
S-Au was observed for a senes of dithiols excludes the formation of looping structure in the dithol SAMs investigated.

The above results are different from the previous study. ${ }^{+8}$ in which the reductive charge more than that of a full monoalyer was observed. A partially formed intralayer disulfide bond on top of dithol SAMs was proposed and the extra charge was suggested to be due to the dissociation of the disulfide bond. But this explanation cannot match with the fact that the bond energy of disulfide is ligher than that of sulfur-Au bond. in which the breaking of S-Au bond and the dissociation of disulfide bond can not take place simultaneously and therefore, the charge corresponded to these two process will not mix together. 1.269

Theoletical Calculation. Molecular dy namics calculations for each SAMs were performed for $100 \mathrm{ps}$ and $\mathrm{Ins}$ for $\mathrm{l}^{\text {st }}$ and $2^{\text {nd }}$ sinulation, respectively, at $300 \mathrm{~K}$. The angles of the monothiol and dithiol molecules in each SAM were collected from their optinized structure after the $2^{\text {nd }}$ molecular dy nanics. The plots of population as a function of tilt angle of SAMs with different carbon numbers are shown in Figure 5. It shows that with increase of alkyl chain length. the tilt angles of molecules in SAMs slightly increased and most were around 20 - 35 degree. In the mean tume, the molecular population peak became narrow and sharp. which indicates a relatively disordered SAM with shorter chain length and a highly
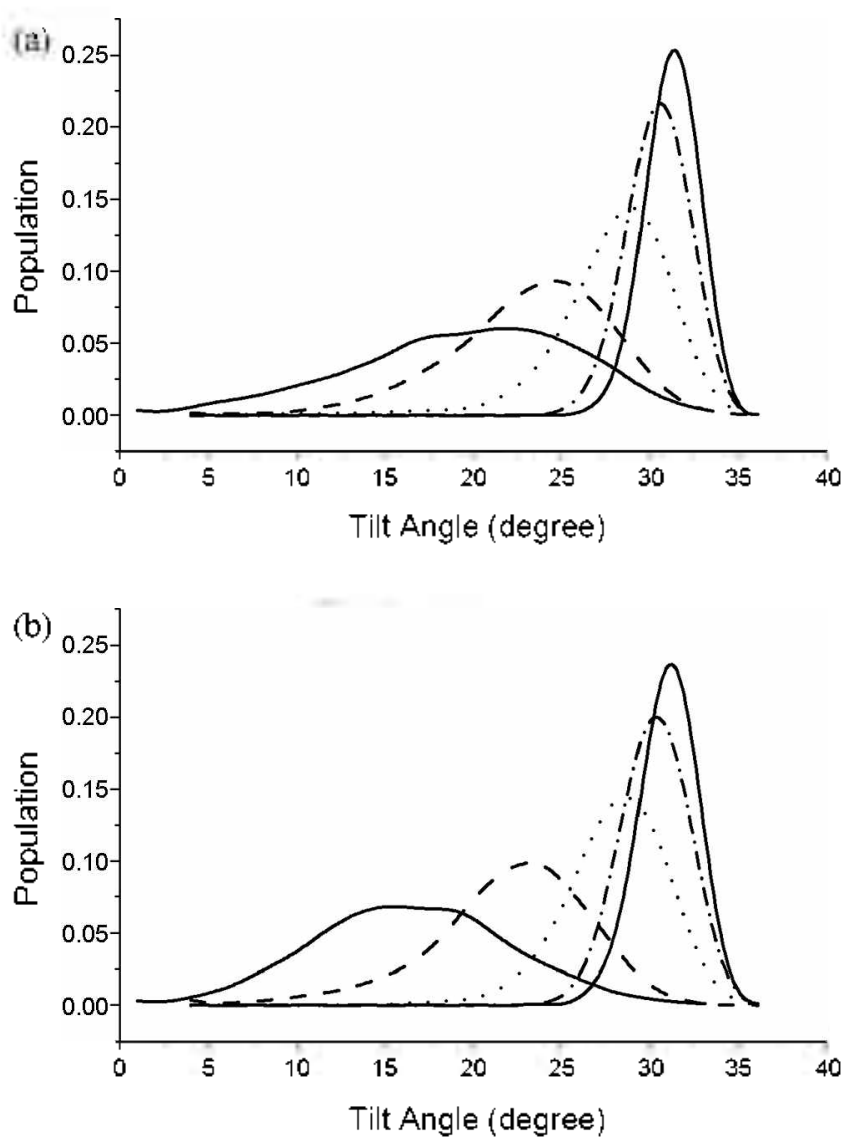

Figure 5. Plots of population versus tilt angle of simulated monothiol (a) and dithiol (b) molecules in the SAMs with different number of carbons: $\mathrm{C} 2$ (full line), $\mathrm{C} 4$ (dash line), $\mathrm{C} 6$ (dotted line), $\mathrm{C} 8$ (dashdotted line), C10 (tull line). 


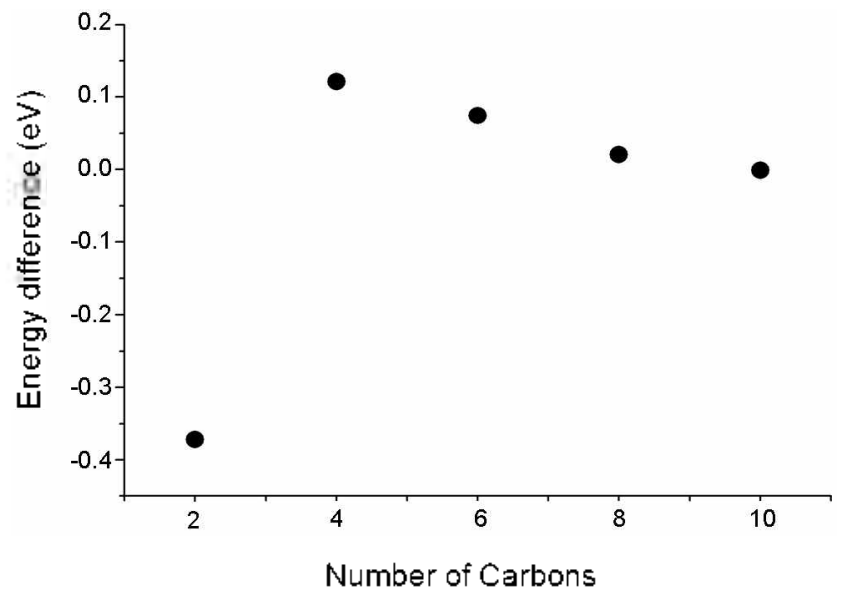

Figure 6. Calculated tree energy difterences between monothiol and dithiol SAMs as a function of alkyl chain length.

orientated SAM with longer chain. This agrees with the experimental observation that the SAMs of short alkanethiol were liquid-like and became solid crystalline-like when the chain length was increased. ${ }^{\text {in }}$ It also agrees well with the fact that the tilt angle for the SAMs of longer alkylthiol is 30 degree. ${ }^{1.64}$ It is interesting to note that those optimized structures of dithiol SAMs. except ethanedithiol are similar to those of corresponding monothiol ones. suggesting that the alkyl chain of dithiol molecule in SAMs has all trans conformation

The potential energies of SAMs for monothiol and dithiol were obtained by calculating the potential energy of center molecule in the SAMs. The energy differences between monothiol and dithiol SAMs were plotted as a function of alkyl chain length in Figure 6. Similar to those experimental results shown in Figure 4. except ethanedithiol the energy differences between monothiol and dithiol SAMs decrease with chain length increased. In case of the ethanedithiol SAM. it was found that its energy was even higher than that of ethanethiol SAM (1.19 eV and $0.82 \mathrm{eV}$ for ethanedithiol and ethanethiol. respectively). This may be the reason that due to their unstable structure, a monolayer of ethanedithiol can not be formed. Instead a bilayer will be formed on $\mathrm{Au}$ by $\mathrm{C} 2 \mathrm{~S} 2$ even in its sub-monolayer coverage. ${ }^{46}$

\section{Conclusion}

Densely packed and highly ordered $1, n$-alkanedithiol $(\mathrm{n}=2$. 4. 6. 8. 10) SAMs with an upright molecular structure, in which all dithiol molecules were found to be bound to the substrate via the thiolate link from one of the thiol groups and the second one free at the SAM-ambient interface. were formed on a $\mathrm{Au}(111)$ substrate. A high stability of dithiol SAMs compared to their corresponding monothiol SAMs was confinned by the observation of a negative reductive peak potential shift from monothiol SAMs to dithiol SAMs. The highly stabilized effect of S-S intralayer interaction on the thiol terminated dithiol SAMs surface was thought to be the main cause. The theoretical calculation demonstrated that the dithiol and monothiol SAMs have the similar structure. The calculated free energies of mono and dithiol SAMs showed the same trend as observed by experimental means. Ethanedithiol was found to form a bilayer due to its unstable structure of monolayer.

Acknowledgments. This work was financially supported by Korea University.

\section{References}

1. Love, A. C.; Estroff, L. A.; Kribel, J. K.; Nuzzo, R. G.; Whitesides, G. M. Chent. Rev 2005, 105, 1103.

2. Ulman, A. An Introduction to Zltw-Thin Organic Films from Langmir-Blodgett to Self.4ssembly; Academic press, San Diego; 1991 .

3. Li, C.; Pobelov, 1.; Wandlowski, li; Bagrets, A.; Amold, A.; Evers, F. J. Am. Chem. Soc. 2008, 130, 318.

4. Boer, B.; Frank, M. M.: Chabal, Y. I.: Tiang, W.: Gartunkel, E.; Bao, 2. Langmuir 2004, 20, 1539.

5. Ohgi, T.; Sheng, H.-Y.; Nejoh, H. Appl. Suff. Sci. 1998, 130-132, 919

6. Ohgi, T.; Sheng, H.-Y; Dong, Z.-C; Nejoh, H, Fujita, D. Appl. Phus. Letr. 2001, 79, 2453.

7. Andres, R. P.: Bein, T.; Dorogi, M.; Feng, S.: Henderson, I. I.; Kubiak, C. P.; Mahoney, W; Osifchin, R. G.; Reitenberger, R. Science 1996, 272, 1323 .

8. Ohgi, T.; Sheng, H.-Y.; Dong, Z.-C.; Nejoh, H. Surf. Sci, 1999. $4+2,277$

9. Esplandiu, M. T.; Noeske, P.-L. M. Appl. Siwf. Sci. 2002, 199, 166.

10. Tarlov, M. J. Langmir 1992, 8, 80.

11. Ongi, T.: Fujita, D; Deng, W.; Dong, Z-C :; Nejoh, H. Suf. Sci. $2001,493,453$

12. Speets, E. A.; Ravoo, B. T.; Roesthuis, F. I. G.; Vroegindeweij, F, Blank, D. H. A.; Reinhoudt, D. N. Nomo Lett. 2004, t, 84l.

13. Speets, E. A.: Dordi, B.; Ravoo, B. J.: Oncel, N.: Hallback, A.-S.: Zandvliet, H. I. W.; Poelsema, B.: Rijnders, G.; Blank, D. H. A.: Reinhoudt, D. N. Small 2005, 1, 395.

14. Cui, X. D.; Primak, A.; Zarate, X; Tomtohr, T; Sankey, O. F.; Moore, A. L.; Moore, T. A.: Gust, D.; Hamis, G.: Lindsay, S. M. Science 2001, 294, 571

15. Xiao, Y.; Patolsky, F.; Katz, E.; Hainteld, T. F.; Willner, I. Science 2003, 299, 1877.

16. Ramachandran, G. K.: Hopson, T. T.; Rawlett, A. M.: Nagahara, L. A.; Primak, A.; Lindsay, S. M. Science 2003, $300,1413$.

17. Zheng, I.; Zhou, Y.: Li, X.; Ji, Y.; Lu, T.: Gu, R. Langmwi 2003, 19,632

18. Baunach, T.; Ivanova, V.; Kolb, D. M.; Boven, H.-G.; Ziemann, P.: Buttner, M: Oelhafen, P. Adv Mater. 2004, 16, 2024.

19. Ivanova, V:; Baunach, T.: Kolb, D. M. Electrochim .1cta 2005 , 50,4283

20. Manolova, M.; Ivanova, V.; Kolb, D. M.; Boyen, H.-G.; Ziemarm, P.: Buttner, M.: Romanyuk, A.; Oelhaten, P. Surf. Sci. 2005, 590,146

21. Manolova, M; Kayser, M; Kolb, D. M: Boyen, H.-G.; Ziemant, P.; Mayerc, D.; Wirth, A. Electrochim Acta 2007, 52 , 2740 .

22. Qu, D.: Uosaki, K. Chem. Let 2006, 35(3), 258

23. Qu, D.: Uosaki, K. J. Phys. Chem. B 2006, 110, 17570

24. Sivanesan, A; Kanuan, P.; Abraham John, S. Electrochint .Acto $2007,52,8118$

25. Rajalingam, K.: Strunskuls, T.; Tertort, A.; Fischer, R. A.; Woll, C. Langmuir 2008, 24, 7986 .

26. Riskin, M.; Basnar, B.; Chegel, V. I.; Katz, E.; Willner, I.; Shi, F.; Zhang, X. J. Ant Chem Soc. 2006, 128,1253

27. Burst, M.: Blass, P. M.: Bard, A. J. Langmir 1997, 13, 5602.

28. Deng, W.; Yang, L : Fuịta, D.; Neioh, H.; Bai, C. Appl Phs. A $2000,71,639$. 
29. Venkataramanan, M.: Murty, K. V. G. K.: Pradeep, T.: Deepali, $\mathrm{W}$ : Vijayamohanan, K. Langmuir 2000, 16, 7673.

30. Nakanishi, T.; Ohtani, B.; Shimazu, K.: Uosaki, K. Chem. Phys. Left. $1997,278,233$

31. Nakanishi, T: Ohtani, B.: Uosaki, K. J. Phys. Chen. B 1998, 102,1571 .

32. Kohli, P.; Taylor, K. K.; Harris, J. J.: Blanchard, G. J. J. Am. Chem. Soc. 1998, I20, 11962

33. Rifai, S.; Laferriere, M.: Qu, D.; Wayner, D. D. M.; Wilde, C. P.: Morin, M. J. Electroanal Chem. 2002, 531, 111 .

34. Rifai, S.: Morin, M. J. Electroanal. Chem. 2003, 550-551, 277.

35. Rifai, S.; Lopinski, G. P.; Ward, T.; Wayner, D. D. M.: Morin, M. Langnnir 2003, 19,8916.

36. Reed, M. A.; Zhou, C.: Muller, C. T.; Burgin, T. P.: Tour, J. M. Science 1997, 278, 252.

37. Akkerman, H. B.: Naber, R. C. G.: Jongbloed, B.: van Hal, P. A. Blom. P. W. M.; de Leeuw, D. M.; de Boer, B. Proc Katl . Acad. Sci. 2007, 104, 11161

38. Akkerman, H. B.: Kronemeijer, A. J.: van Hal, P. A.; de Leeuw, D. M; Blom, P. W. M:; de Boer, B. Small 2008, t, 100 .

39. Leung, T. Y. B.: Gerstenberg, M. C.; Lavrich, D. T.: Scoles, G. Langnnit 2000, 16, 549 .

40. Shon, Y. S.; Colorado, R.; Williams, C. T.; Bain, C. B.: Lee, T. R. Langmmir 2000, 16, 541 .

4l. Murty, K. V. G. K.: Venkataramanan, M.; Pradeep, T. Langmuir $1998,1+5446$.

42. Lee, T. G.; Kim, K.; Kim, M. S. J. Phys Chem 1991, $95,9950$.

43. Kwon, C. K.: Kim, K.: Kin, M. S.: Lee, Y. S. J. Mol Strtat. $1989,197,171$.

44. Cho, S. H.: Han, H. S.; Jang, D.-T.: Kim, K.; Kim, M. S. J. Phn's. Chem. 1995, 99, 10594.

45. Tour, J. M.: Tones, L., II; Pearson, D. L.: Lanba, I. S.: Burgin, T P.; Whitesides, G. M.; Allara, D. L.: Parikh, A. N.; Atre, S. V. J. An. Chent. Soc. 1995, 117, 9529

46. Too, S. W.; Han, S. W; Kim, K. Langmiri 2000, 16, 5391.

47. Tai, Y.: Shaporenko, A.: Rong. H.-T.: Buck, M: Eck, W.: Grunze, M.: Zhantikov, M. J. Phys. Chem. B 2004, $108,16806$.
48. Carot, M. L.; Esplandiu, M. I.: Cometto, F. P.: Patrito, E. M.; Macagno, V. A. J. Electroanal Chem. 2005, 579, 13.

49. Esplandiu. M. I.: Carot. M. L.: Cometto. F. P.: Macaono. V. A.: Patrito, E. M. Surf. Sci. 2006, 600, 155.

50. Pugmire, D. L.; Tarlov, M. T.; Zee, R. D. V.; Naciri, J. Langmuir $2003,19,3720$

51. Too, S. W.: Han, S. W.; Kim, K. J. Phus Chem. B 1999, 103. 10831 .

52. Azzam, W.: Weluer, B. I.; Fischer, R. A.; Terfort, A.; Woll, C. Langmir 2002, 18, 7766 .

53. Niklewski, A.; Azzam, W.: Strunskuls, T.; Fischer, R. A.; Woll, C. Langmuir 2004, 20,8620.

54. Liang, T.; Rosa, L. G.; Scoles, G. J. Phys. Chem. C 2007, 11, 17275 .

55. Garcia-Raya, D:; Madueno, R.: Sevilla, I. M.: Blazqulez, M.; Pineda, T. Electrochim. Acta 2008, 53,8(26.

56. Vandamme, N.; Snauwaert, T.; Janssens, E.; Vandeweert, E.; Lievens, P: Haesendonck, C. V. Surf. Sci. 2004, 558, 57

57. Sur. U. K.: Subramanian. R.: Lakshminarayanan. V. J. Colloid Interface Sci. 2003, 266, 175.

58. Clavilier, J.; Faure, R.; Guinet, G.; Durand, R. J. Electromal. Chent 1980,107, 205.

59. HyperChem, Release 7.5 for windows; Hypercube, Inc

60. HyperChem Manual; Hypercube, Inc. Tan. 2002.

61. Allinger, N. L. J. Am. Chem. Soc. 1977, 99,8127.

62. Yang, D.-F : Wilde, C. P.) Morin, M. Langmitr 1996, 12,6570

63. Yang, D.-F.; Wilde, C. P.; Morin, M. Langmuir 1997, 13, 243.

64. Fenter, P.: Eberhardt, A.; Liang, K. S.: Eisenberger, P. J. Chem. Phus 1997, 106, 1600 .

65. Sclureiber, F. Prog. Sirf. Sci. 2000,65, 151.

66. Qu, D.; Morin, M. J. Electroanal. Chem. 2001, 517, 45.

67. Sumi, T.: Wano, H.: Uosaki, K. J. Electroanal Chem. 2003. $550-551,321$

68. Sumi, T.; Uosaki, K. J. Phys. Chem. B 2004, 108,6422

69. Borsari, M: Cantio, M: Gavioli, G. Electrontal 2003, 15, 1192

70. Porter, M. D.: Bright, T. B.; Allara, D. L.: Chidsey, C. E. D. J. Am. Chem. Soc. 1987, 109, 3559 . 